\title{
Proximidad territorial y desarrollo local - rural: las ferias francas de la Provincia de Misiones - Noreste Argentino*
}

Territorial neighborhood ans sustainable development - rural: the free fairs of missiones province - Argentinian Northeast

\author{
Proximité territorial et devéloppment soutenable - rural: les faires libres de la \\ province de missiones - Nord-est Argentin \\ Proximidade territorial e desenvolvimento local - rural: as férias francas da Provincia de \\ Misiones - Nordeste Argentino
}

\author{
María Andrea Nardi** \\ Sandra Graciela Pereira***
}

Recebido em 15/7/2005; revisado e aprovado em 16/12/2005; aceito em 5/3/2006.

\begin{abstract}
Resumen: El concepto de proximidad tiene sus orígenes en Francia, a principios de los años '90, con los estudios realizados por el Grupo de la Dinámica de la Proximidad. La importancia de la proximidad territorial para el desarrollo se visualiza básicamente a través de estudios centrados en el análisis de dinámicas industriales y ambientes innovadores. Su relación con el desarrollo local en áreas rurales pobres ha sido poco considerada. En este trabajo se intenta avanzar en la comprensión del desarrollo local rural desde una perspectiva centrada en las relaciones de proximidad, tomando como objeto de estudio el proceso de conformación de la primera feria franca en la provincia de Misiones, ubicada en el noreste argentino.

Palabras clave: Proximidad; Desarrollo Local; Desarrollo Rural.
\end{abstract}

\begin{abstract}
The concept of proximity has its origins at the beginning of the years' 90 in France with the studies from the Group of the Dynamics of the Proximity. The importance of the territorial proximity for the development is considered basically through studies centred in the analysis of industrial dynamic and innovative environments. Its relationship with the local development in poor rural areas has been almost not considered. This work attempts to advance in the understanding of the local rural development from a perspective centred in the relationships of proximity focusing in the process of conformation of first local farmers' fairs in Misiones, North-eastern Argentina.

Key words: Proximity; Local development; Rural development.

Résumé: Le concept de proximité a ses origines en France, au début des années 90, avec les études faites par le Groupe de la Dynamique de la Proximité. L'importance de la proximité territoriale pour le développement se visualise basiquement dans les études centrées sur des analyses de dynamiques industrielles et milieux innovateurs. Sa relation avec le développement local dans des régions rurales pauvres a été peu considérée. Ce travail a essayé d'avancer dans la compréhension du développement rural local à partir d'une perspective centrée sur les relations de proximité, prennant comme objet d'étude le procédé de conformation de la première foire libre dans la province de Misiones, située dans le Nord-est de l'Argentine.

Mots-clé: Proximité; Développement Local; Développement Rural.

Resumo: O conceito de proximidade tem suas origens na França, no início dos anos '90, com os estudos realizados pelo Grupo da Dinâmica da Proximidade. A importância da proximidade territorial para o desenvolvimento visualizase basicamente por estudos centrados na análise de dinâmicas industriais e ambientes inovadores. Sua relação com o desenvolvimento local nas áreas rurais pobres tem sido pouco considerada. Neste trabalho procura-se avançar na compreensão do desenvolvimento local rural, a partir de uma perspectiva centrada nas relações de proximidade, tomando como objeto de estudo o processo de conformação da primeira feira livre na Provincia de Misiones, situada no nordeste argentino.
\end{abstract}

Palavras-chave: Proximidade; Desenvolvimento Local; Desenvolvimento Rural.

\section{Introducción}

La idea central de nuestro análisis es que para mejorar la calidad de vida y alcanzar una distribución equitativa de los ingresos en los ámbitos rurales-pobres de
América Latina, es fundamental la interacción continua y permanente entre el accionar del Estado (organismos de gestión, de investigación, de salud, de educación) y de las organizaciones cooperativas y solidarias (ONG, iglesias, cooperativas,

\footnotetext{
* Este trabajo se ha realizado en el marco de investigación del Programa de Economías Regionales y Estudios Territoriales (PERT) del Instituto de Geografía de la Universidad de Buenos Aires (UBA). Para dicha investigación se cuenta con apoyo financiero de la UBA y de la Agencia Nacional de Promoción Científica y Tecnológica (ANPCyT). Puán 480, $4^{\circ}$ piso (1406) Ciudad de Buenos Aires. Tel.: +54 (11) 4432-0606 int.-169.

** Licenciada en Geografía. Investigadora del PERT, Instituto de Geografía de la UBA. (anardi@filo.uba.ar).

*** Licenciada en Geografía. Investigadora del PERT, Instituto de Geografía y Profesora del Departamento de Geografía, Facultad de Filosofía y Letras, UBA. (sanper@filo.uba.ar).
} 
cooperadoras, gremios, sindicatos, etc.) que se encuentran trabajando en el sector de pequeños productores. En tal sentido, estamos de acuerdo con Manzanal (2004, p.12) cuando sostiene que "las diversas y variadas formas de participación de la población local, reclamando y expresando sus demandas sociales y económicas en forma organizada, articulándose con otras organizaciones, son una condición necesaria para la generación, promoción y sostenimiento de un modelo de desarrollo territorial, regional o rural-local alternativo (eficiente, productivo, distributivo, sostenible, transparente)".

Desde esta perspectiva, tomamos como caso de estudio el proceso de organización de ferias francas en la provincia de Misiones. Estas experiencias de comercialización directa del pequeño productor al consumidor se llevan a cabo en ámbitos locales en donde se ha dado una movilización social importante que ha sabido aprovechar la capacidad institucional existente en la provincia, y los espacios generados y las acciones promovidas por programas de intervención en el medio rural. El accionar conjunto de diferentes organizaciones y organismos ha permitido la conformación de estos emprendimientos innovativos.

El objetivo del presente trabajo es realizar un análisis centrado en las relaciones de proximidad entre las organizaciones consideradas precursoras en el proceso de conformación y consolidación de la primera feria franca misionera.

\section{Contexto de análisis}

La situación de cambio y crisis socioeconómica ${ }^{1}$ generalizada en Argentina durante los años '90 tuvo un fuerte impacto en las economías regionales caracterizadas por la mayoritaria presencia de pequeños y medianos productores agropecuarios vinculados a cultivos tales como la yerba mate, el té, el tabaco, el algodón, el azúcar, el pimiento, la uva, etc. ${ }^{2}$. Las mismas han sido las más afectadas por su limitada o incluso inexistente capacidad de ofrecer actividades alternativas a las producciones que se desarrollaban en su territorio. En este contexto se observa una restricción del acceso al mercado (tanto de bienes como de servi- cios) de los productores más pequeños, lo que ha definido un importante deterioro de su calidad de vida.

Como consecuencia, este sector se ve forzado a buscar caminos alternativos y a adoptar estrategias innovativas para hacer frente a esta situación. En la mayoría de los casos, emprendieron nuevas actividades que se encuentran por fuera de la cadena productiva en la que estaban insertos. Algunas de estas nuevas estrategias se basaron fundamentalmente en la consolidación de procesos organizativos. En estos casos, la participación y capacitación de los actores sociales contribuyó a favorecer y fortalecer los mecanismos locales de toma de decisiones, así como también, la gestión de los recursos naturales y humanos existentes en el territorio.

Los principales actores intervinientes en este proceso han sido: a) el Estado - nacional, provincial y municipal -; b) las organizaciones no gubernamentales -ONGinternacionales, nacionales, provinciales y locales; y c) los pequeños y medianos productores agropecuarios organizados ${ }^{3}$.

A partir de los primeros años de la década del '90, el estado nacional comenzó a implementar programas destinados a los sectores más vulnerables de la población, sin que esto haya significado la puesta en marcha de una política de desarrollo. Específicamente en el área de "desarrollo rural", la Secretaria de Agricultura, Ganadería, Pesca y Alimentación de la Nación (SAGPyA) puso en marcha varios programas dirigidos a los pequeños y medianos productores agropecuarios ${ }^{4}$. Para la ejecución de algunos de los mismos, se aprovechó la capacidad institucional y organizativa acumulada por las ONG's en los espacios rurales en donde venían desarrollando distintas experiencias con pequeños productores. En este proceso se priorizó también la articulación entre las organizaciones existentes -de productores, cooperativas, gremios, etc.- y la promoción de la participación, la organización y la capacitación de la población beneficiaria.

Las ONG's de desarrollo rural, vienen trabajando en ámbitos locales de nuestro país desde los años '80. Las mismas crecieron en número, en coincidencia con la vuelta de la democracia en 1983. Históricamente pueden 
identificarse diferentes momentos o etapas en cuanto a las estrategias de trabajo utilizadas y a la cantidad acciones realizadas por las mismas. Según Benencia y Flood (1998, p.57) "operan como ámbitos para la canalización de recursos, como espacios para el desarrollo de metodologías alternativas y flexibles de trabajo y para la formación de cuadros técnicos". Durante los años '90, estas organizaciones tomaron a su cargo algunas de las funciones delegadas por el 'Estado de Bienestar' en franca desaparición (particularmente en la gestión de políticas sociales) y a mediados de esta década, las ONG's se difundieron por todo el territorio argentino atendiendo diversas problemáticas, no siempre con objetivos y propósitos claros.

También en este período se conforma un movimiento nacional de pequeños productores. La Mesa Nacional de Organizaciones de Productores Familiares comenzó a funcionar en 1995 con la paulatina participación de organizaciones representativas de aquel sector que venían ya consolidándose en diferentes provincias desde principios de los '90 (el Movimiento Campesino de Santiago del Estero -MOCASE ${ }^{5}$ ) e incluso mucho antes (el Movimiento Agrario Misionero $\left.\mathrm{MAM}^{6}\right)$, a las que se agregaron la Asociación de Productores del Norte de Córdoba (APENOC), la Red Puna en Jujuy y el Movimiento Campesino de Formosa (MOCAFOR), entre otras.

En este contexto de cambio y reestructuración institucional en Argentina, surgen las ferias francas de Misiones como una estrategia innovativa ante la imposibilidad de que las producciones tradicionales de la provincia -yerba mate, té y tabaco- pudieran garantizar el bienestar de los pequeños productores. Las ferias ${ }^{7}$ se presentan como una forma alternativa de inserción del productor al mercado que le posibilita un ingreso constante, al privilegiar la producción de consumo familiar sobre la producción tradicional ${ }^{8}$. En esta actividad de producción y venta directa los pequeños productores participan en el mercado local contribuyendo al abastecimiento de productos frescos.

Los beneficios que obtienen los productores por participar en la feria, en comparación con la actividad productiva tradicional, han sido mencionados en varios trabajos basados en estudios de caso (véanse al respecto PSA, 1997; CATTÁNEO, 1999; CARBALLO, 2000; SCHVORER, 1999). En los mismos, haciendo referencia a diferentes ferias de la provincia, se muestra que estos emprendimientos se adaptan al contexto local y al sector pequeño productor, ofrece ingresos permanentes en forma semanal, requiere baja inversión inicial y tiene riesgos y costos operativos reducidos (PEREIRA y TAIPALE, 2004). Además, se observa un aumento de la autoestima de los productores por sentirse partícipes de la sociedad local y "salir de las colonias para ir al pueblo".

Todo esto ha permitido a los feriantes superar los obstáculos existentes en el entorno territorial para la consolidación, difusión y desarrollo de esta estrategia en más de cuarenta localidades de la provincia. Sin embargo, un factor fundamental que obstaculiza la consolidación de algunas ferias es la relativamente débil demanda y la incapacidad de ampliar el mercado, así como también, cuestiones de infraestructura básicas que dificultan el traslado de los productores feriantes hacia las localidades.

\section{La importancia de la proximidad territorial para el desarrollo local - rural}

Si consideramos que el territorio se origina en las acciones y prácticas de los agentes y las instituciones que las enmarcan, podríamos decir entonces, que el análisis territorial implica observar la trama de relaciones entre la dimensión socio-económica y la dimensión institucional. Según esta noción del 'territorio', los agentes y las instituciones se constituyen en promotores directos del proceso productivo y no en una externalidad (BOSCHERINI y POMA, 2000). De esta forma, el territorio no es neutral y asume un nuevo rol, definido según sus capacidades de aprovechamiento de recursos sociales y físicos, y teniendo en cuenta las principales relaciones de proximidad.

Desde esta perspectiva analítica el territorio local tiene una particular conceptualización: es la trama resultante de los comportamientos institucionalizados y localizados en un determinado espacio de agentes sociales (individuales y colectivos), que se vinculan por medio de distintos tipos de 
actividades con cierta regularidad. De esta forma, podemos definir el ámbito local como un territorio caracterizado y delimitado básicamente por la posibilidad 'espacial' (en tiempo y distancia) para practicar interacciones frecuentes y regulares entre sus habitantes (éstos pueden vivir en una o más áreas de población aglomerada ó en la zona rural circundante) (MANZANAL, 2004, p.16).

Nos ocupamos puntualmente del 'desarrollo local - rural' porque se trata del desarrollo del territorio local, del lugar donde la población localizada tiene posibilidades de organizarse y proyectarse para influir, e incluso tomar las decisiones que la involucran y que tienen que ver con la política y con el ámbito de lo público. Así, los actores locales tienen un rol central en el desarrollo ya que el ámbito local es el lugar donde la población puede accionar políticamente, es en el ámbito local en donde personas ejercen su praxis cotidiana (Pfr. MANZANAL, 2004).

En un sentido más amplio, entendemos el desarrollo local - rural como un punto de partida para trascender a ámbitos mayores, superando lo sectorial agropecuario. Se trata de considerar al desarrollo rural como una dimensión del desarrollo local y al mismo tiempo, ambos como parte de procesos y variables que operan en el ámbito nacional, regional y mundial, que es necesario considerar, en definitiva, el desarrollo territorial.

El rol activo de los agentes locales en el proceso de desarrollo local, supone el fortalecimiento continuo de su participación en espacios de toma de decisiones. Existe cierto acuerdo en que la participación es "un proceso por el cual las personas, especialmente los individuos en desventaja, influyen sobre las decisiones que los afectan" (BRETT, 1999, p.4). Concordamos con este autor en que la participación implica educación y capacitación de las personas, asociadas y organizadas entre sí y con otros actores, para identificar problemas y necesidades, movilizar recursos, y asumir responsabilidades para planificar, administrar, controlar y evaluar las acciones individuales y colectivas sobre las cuales ellos deciden. Suponemos también que el punto clave de la participación es compartir el poder, lo cual permite recrear/modificar las relaciones de dependencia (KLIKSBERG, 2000). Es el marco ins- titucional, tanto formal como informal, el que llevado a la práctica, posibilita o limita el desarrollo todo este proceso participativo y organizacional de la población local.

De acuerdo a nuestra perspectiva analítica, consideramos a las instituciones como las normas o reglas que enmarcan los comportamientos individuales y colectivos, "...los actores calculan sobre la base de sus intereses pero también están equipados con diversas visiones del mundo, según su posición social y los contextos sociales (...) Cálculo y cultura se combinan en la constitución de actores colectivos que actúan en el marco de macro instituciones heredaras y de relaciones de poder asimétricas". En este sentido, "la institución es normativa y creadora del orden social" (BRUNO THÉRET, 2000, p.3). El concepto de institución que proponemos no solamente incluye aspectos normativos, sino también aspectos reguladores y cognoscitivos.

En su estudio sobre desarrollo y cambio institucional, North (1993, p. 13) considera que las instituciones son "las limitaciones ideadas por los hombres que dan forma a la interacción humana. Por consiguiente estructura incentivos en el intercambio humano, sea político, social o económico". Se trata de las reglas de juego que reglamentan el comportamiento de las organizaciones y que pueden ser formales o informales, explícitas o implícitas, pero aceptadas y conocidas por todos los involucrados (ESPINO, 1999). Las instituciones son eficientes si permiten generar condiciones para que los individuos realicen elecciones estables y propicien la coordinación de decisiones colectivas. De allí su importancia en la implementación de mecanismos participativos, para que los actores locales entren en vinculaciones de cooperación, de articulación.

Por su parte, las organizaciones son los "grupos de individuos unidos por un propósito común, para alcanzar sus objetivos" (NORTH, 1995, p.23), son "las instancias o arenas en las cuales los individuos se relacionan y organizan en grupos para emprender acciones cooperativas y actuar como 'actores colectivos' (...) por supuesto, de acuerdo con las reglas contenidas en las instituciones existentes" (ESPINO, 1999, p.65). Por lo tanto, las organizaciones "son entidades construidas en torno a procesos definidos que asegu- 
ran el logro de objetivos determinados. La estructura organizacional se basa en la definición de roles y funciones distintas, y las reglas organizativas deben asegurar un desempeño confiable" (APPENDINI y NUIJTEN, 2002, p.76). Mientras que las instituciones están más definidas en términos de creencias, normas y reglas que permiten el desarrollo de funciones y estructuras, las organizaciones estarían más definidas en términos de esas estructuras que son reconocidas y aceptadas.

\subsection{Proximidad territorial}

El concepto de proximidad territorial se refiere a las temáticas que tienen que ver con el alejamiento entre los individuos, las organizaciones y sus acciones. Por lo tanto, desde nuestra perspectiva, lo podemos considerar como un concepto que integra la idea anterior de territorio con aquellas referidas a instituciones y organizaciones. La proximidad alude a la separación o distanciamiento económico o geográfico entre los actores (individuales o colectivos) dotados de distintos recursos y a las relaciones que los acercan y/o alejan en los procesos orientados a solucionar un problema económico (GILLY y TORRE, 2000).

Siguiendo a Gilly y Torre, el concepto de proximidad está integrado por dos componentes principales: la proximidad geográfica y la proximidad organizacional. La proximidad geográfica se refiere a la separación en el espacio, a vínculos en términos de distancia, a la noción de espacio geoeconómico o distancia funcional, a la circulación relacionada con la accesibilidad. No alude solamente a la distancia física, tiene su fundamento social, por lo menos con respecto a la infraestructura. La proximidad organizacional se refiere a la separación económica que existe entre los actores, los individuos, las distintas organizaciones, a vínculos en términos de la organización de la producción, a la circulación de flujos. La misma se basa en dos categorías lógicas que son la similitud y la pertenencia. "De acuerdo a la lógica de la pertenencia se consideran próximos en términos organizacionales los actores pertenecen al mismo espacio de relaciones, (...) los que se parecen, es decir, que tienen el mismo espacio de referencia y comparten los mismos conocimientos" (GILLY y TORRE, 2000, p.268).

Otros dos componentes son la proximidad institucional (que se refiere a la separación institucional, expresa la adhesión de los agentes a un espacio de representatividad, de modelos y de reglas de pensamiento y de acción comunes); y la proximidad territorial (como intersección/superposición de las principales formas de proximidad). La primera evidencia el rol desempeñado por las instituciones y permite definir al territorio como un proceso de coincidencia/articulación entre las proximidades geográficas, organizacionales e institucionales (GILLY y TORRE, 2000).

La noción de proximidad hace referencia a la existencia de interacciones, las cuales pueden ser intencionales (relaciones de cooperación, de confianza, de intercambio, etc.) y no intencionales (externalidades, economías de aglomeración): "la intencionalidad presente en la acción revela el potencial escondido en la relación entre la proximidad geográfica y la proximidad organizacional" (GILLY y TORRE, 2000, p.268-271), ya que supone la voluntad de interactuar de los participantes con objetivos en común y visualizando un mutuo beneficio como resultado de la cooperación.

La importancia y la frecuencia de las interacciones dan cuenta del dinamismo y es por ello que a partir de la densidad más o menos acentuada y amplia que tienen las interacciones, se pueden definir los procesos de separación/unión y de acercamiento/alejamiento, entre actores, organizaciones y actividades. La definición de densidad de las interacciones tiene en cuenta no sólo el número de las mismas sino también la posibilidad de reproducción, la duración y el grado de transitividad. La densidad de las interacciones se modifican en el tiempo y constituye un indicador organizacional y de la proximidad geográfica (GILLY y TORRE, 2000).

En resumen, la noción de territorio que proponemos condensa los conceptos de participación, instituciones y organizaciones. La noción de proximidad, hace referencia a los factores territoriales que posibilitan o restringen el acercamiento entre los actores. 
3.2 Las relaciones de proximidad en la creación de la primera feria franca de Misiones

Entendemos que la concreción de la feria franca es el resultado de la interacción continua de distintos tipos de organizaciones y de los propios productores - feriantes. La cooperación de diversos actores se visualizó en la práctica como una mayor posibilidad de éxito. Y es así que las ferias funcionan como organizaciones que persiguen un objetivo común de acuerdo a las instituciones existentes y las que ellas mismas van creando.

Varios elementos contribuyen a la construcción de la proximidad geográfica dentro del territorio de la provincia. La superficie total de Misiones es de $29.801 \mathrm{~km}^{2}$. Atraviesan su territorio de norte a sur y de este a oeste dos rutas nacionales, varias provinciales y una importe cantidad de caminos locales, contribuyendo a la proximidad geográfica entre la población, distribuida en 117 localidades ${ }^{9}$.

En Misiones existe una importante cantidad de organizaciones de productores y organismos de intervención en desarrollo rural que centran su accionar en el sector pequeño productor. Si bien algunos de ellos funcionan en forma localizada dentro de la provincia, la proximidad geográfica hace posible el flujo e intercambio de información y personas.

En general, dentro de las organiza- ciones de productores, ONG's y organismos nacionales de intervención en desarrollo rural que actualmente se encuentran trabajando con pequeños productores, se puede reconocer al MAM, al Programa Social Agropecuario (PSA), al Instituto Nacional de Tecnología Agropecuario (INTA) ${ }^{10}$, al Instituto Nacional de Desarrollo Social y Promoción Humana, a la Pastoral Social de la Diócesis de Posadas e Iguazú, a la Red de Agricultura Orgánica de Misiones, a Asociación Ferias Francas de Misiones, como los principales actores del desarrollo local rural en Misiones.

El gobierno provincial actúa en el sector más activamente a través del Programa de Desarrollo Rural de las Provincias del Noreste, del Instituto de Fomento Agropecuario e Industrial y la Dirección de Pequeños Agricultores, Huertas y Ferias Francas.

Varias de estas organizaciones comparten el mismo espacio de relaciones y presentan estrategias de intervención similares hacia el sector. Son próximas entre sí, tanto geográfica como institucionalmente, lo cual contribuyó -con mayor o menor participación- a la creación y posterior difusión de ferias en el territorio misionero.

El siguiente mapa presenta la distribución de las ferias francas y de las localidades con más de 400 habitantes, a la vez que señala la localización de las distintas sedes de trabajo de las organizaciones mencionadas. 
Provincia de Misiones. Ferias Francas y relaciones de proximidad : sedes y delegaciones de las principales organizaciones participantes en la conformación y difusión de las ferias en Misiones

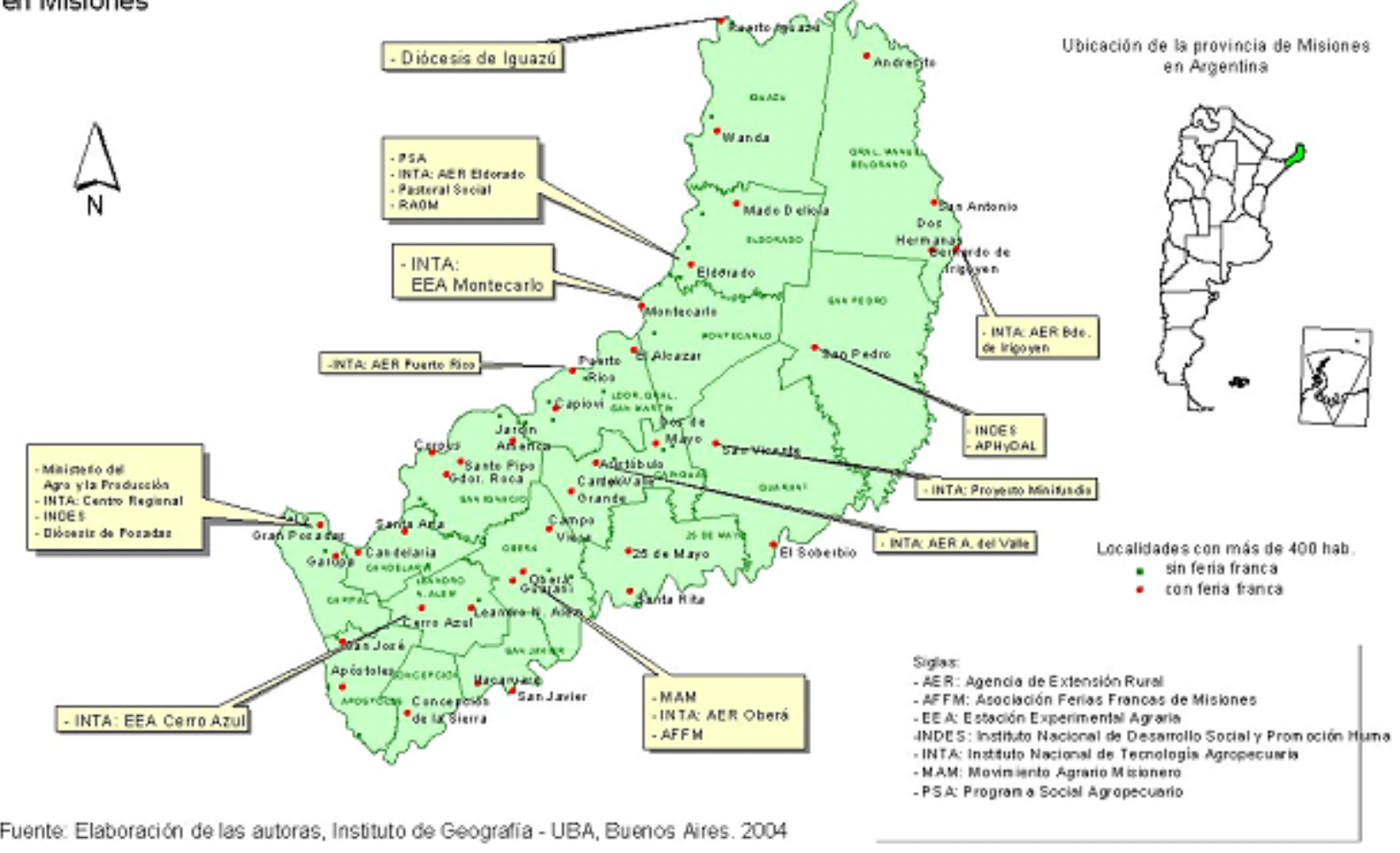

\section{La proximidad de las organizaciones que constituyeron la feria de Oberá}

La primera feria se creó en agosto de 1995 a partir de la iniciativa de productores del departamento de Oberá, algunos de ellos integrantes del MAM, quienes contaron con el apoyo técnico y financiero del PSA y la asistencia del INTA.

En el caso de la conformación de esta feria, consideramos que el MAM y el PSA fueron los precursores de este proyecto en la provincia con el acompañamiento del INTA, por medio del programa Cambio Rural. Por su parte, el gobierno local, acompañó también este proceso iniciado por las organizaciones mencionadas.

El MAM, con sede en la localidad de Oberá, es un movimiento gremial cuyo accionar con los pequeños productores se remonta a los años '70 con las Ligas Agrarias Misioneras. Su creación, en 1971, "promovido en gran medida en las sucesivas convocatorias del Movimiento Rural Cristiano, (...) surgió en un momento histórico caracterizado por la crisis del sector agrario, debido a los problemas de comercialización que sufrían los productores de los cultivos tradicionales (yerba mate, té, tung)" (MONTIEL, 1997, p.35).

Si bien la sede del MAM se encuentra en Oberá, este movimiento tiene una fuerte presencia en algunos departamentos del centro y nordeste de la provincia.

Sus representantes participan en organizaciones y organismos de distinto tipo. Así, por ejemplo, algunos de sus integrantes forman parte del Consejo del Centro Regional Provincial del INTA, de la Unidad Técnica de Coordinación Provincial (UTCP) del PSA, del Consejo Multilateral de Políticas Sociales y Desarrollo Regional del Gobierno de Misiones y de la Federación Agraria Argentina.

El PSA es un programa de desarrollo rural implementado desde la SAGPyA, para ser ejecutado en casi todas las provincias argentinas bajo la responsabilidad de un coordinador y de una UTCP ${ }^{11}$. En Misiones, el mismo comenzó a funcionar a fines del $1993^{12}$ contemplando asistencia financiera (bajo forma de créditos no bancarios) y técnica, capacitación y apoyo al mercadeo. En el caso de la creación y consolidación de la feria de Oberá estos instrumentos de intervención fueron destinados al apoyo de los productores que participaban en este proyecto ${ }^{13}$. 
Actualmente el PSA alcanza a 3.000 productores con proyectos activos, aunque históricamente se superó dicho piso (AGROMISIONES, 2004). Su mayor influencia se encuentra en los departamentos del noreste de la provincia, en donde habitan los productores con mayores niveles de pobreza.

En Misiones, el INTA ${ }^{14}$ tuvo a su cargo desde 1993 hasta principios de 2000, la ejecución del Programa Cambio Rural dirigido a medianos productores de todo el país. Los principales instrumentos del mismo han sido la asistencia técnica y capacitación, que también fueron destinados a los productores feriantes de Oberá.

Teniendo en cuenta las características generales de los actores que participaron en la conformación de la feria de Oberá, es importante detenernos en el análisis de las relaciones de proximidad que los mismos mantuvieron para concretar este proyecto innovativo.

Las interacciones entre el MAM y el PSA, en lo que respecta tanto a la proximidad geográfica como a la institucional, han permitido encausar esfuerzos conjuntos y recursos -sociales y productivos- para que la feria franca de Oberá tuviera éxito y fuera tomada como ejemplo para la organización de las demás ferias, tanto a nivel provincial como nacional.

Estos actores son cercanos en la medida en que coinciden en la promoción del desarrollo de una parte del sector de pequeños productores $\mathrm{y}$ ambos han tomado como propio este proyecto, teniendo así un espacio común de referencia. Existe entre estas dos organizaciones una proximidad institucional, basada en la adhesión de sus miembros a la representatividad, a las reglas comunes de pensamiento y de acción.

Si bien las sedes organizacionales del PSA y del MAM están en localidades distantes (Eldorado y Oberá respectivamente) entre ambas existe una proximidad geográfica, una infraestructura (carreteras, telecomunicaciones, medios de transporte, etc.) que permite la comunicación fluida y constante. Además, al ser miembros del MAM algunos de los que se desempeñan como técnicos en los grupos de beneficiarios del PSA en los departamentos en los que ésta organización gremial tiene influencia, el trabajo cotidiano en el campo permite la creación de espacios de referencia compartidos, que con el tiempo se han ido fortaleciendo.

Podríamos decir que, con relación a este proyecto de comercialización, el MAM y el PSA continúan desarrollando un sentido de pertenencia al mismo. Esto se evidencia en el importante papel que han tenido y aún tienen las instituciones existentes y las que ellos crearon a lo largo de todo el proceso de conformación de este ámbito de comercialización; en la participación y gestión que han ido construyendo y consolidando; así como en las expectativas que poseen con respecto al futuro de las ferias y la proyección de algunas de ellas en el mercado provincial e incluso nacional.

Las interacciones entre el PSA y el MAM, en relación a la feria de Oberá, en todos los casos han sido y continúan siendo intencionales, basadas en la cooperación y confianza mutua, que dan cuenta del 'dinamismo' de este proyecto. Las relaciones han sido duraderas a lo largo del tiempo y se han reproducido, en algunos casos se han modificado, pero desde todo punto de vista se han fortalecido en muchos aspectos. Las mismas se basan en actividades desarrolladas por técnicos, promotores, dirigentes que a pesar de los sucesivos recortes en los recursos económicos, continúan desempeñando su tarea de asesoramiento, capacitación y apoyo solidario a sus beneficiarios.

Respecto a la relación entre el MAM y el INTA, podemos decir que ambas organizaciones han compartido espacios de relaciones y de referencia, fueron semejantes en los orígenes del proyecto de comercialización de la feria de Oberá. En este caso, mantuvieron interacciones intencionales que comenzaron siendo muy próximas y que dejaron de serlo y de reproducirse. Creemos que esto puede deberse, en parte, a que varios productores del MAM fueron beneficiarios de Cambio Rural y al irse retirando este programa, la relación entre el MAM y el INTA fue haciéndose cada vez menos próxima. La poca disponibilidad de recursos ha determinado que en la actualidad este Instituto no desempeñe prácticamente ninguna actividad de apoyo a los integrantes de la feria de Oberá.

Finalmente, consideramos que las interacciones entre el INTA y el PSA, se 
basan en una importante proximidad territorial. Su trabajo conjunto para la creación de la primera feria franca de la provincia ha sido importante. Al tener el PSA la sede en la localidad del Eldorado, éste programa está muy próximo al INTA. No solo se trata de una proximidad geográfica, sino organizacional e institucional.

Como mencionamos anteriormente, un representante del INTA, forma parte de la UTCP del PSA, por lo tanto existe un espacio institucional de referencia. Pero en especial, y a diferencia de la proximidad entre el MAM y el PSA, entre el INTA y este programa hay una proximidad organizacional ya que se trata de dos organismos públicos nacionales ${ }^{15}$. Pero en especial destacamos el hecho de que algunos técnicos del INTA forman parte del programa llevando adelante diversas tareas de apoyo y capacitación. De este modo, en el trabajo de campo cotidiano se crean nuevos espacios de referencia.

Las interacciones entre el PSA y el INTA han sido y continúan siendo intencionales. Relaciones basadas en la cooperación y confianza mutua que han sido duraderas a lo largo del tiempo y se han reproducido e incluso fortalecido. Consideramos que existe cierta complementación entre los recursos sociales y los económicos de ambas organizaciones. Si bien el PSA ha ido recortando su presupuesto, otorga créditos a los grupos de productores, mientras que el INTA, ofrece una importante capacidad técnica en recursos humanos, con lo cual se puede lograr una complementación en su accionar.

Si bien estas tres organizaciones comentadas brevemente, son las que consideramos pioneras en la conformación de la feria de Oberá, no podemos dejar de lado el rol cumplido por el gobierno municipal. Algo fundamental para la concreción de la feria es disponer de un espacio público para su funcionamiento y contar con el control sanitario y bromatológico, tanto de las chacras como de los productos elaborados que llegan a la feria, temas en los que se encuentra directamente involucrada la Municipalidad de Oberá.

Con el transcurso del tiempo y la visualización de los resultados, las autoridades del municipio han reconocido a la feria como un proyecto a rescatar y parte del desarrollo de la comunidad local, aunque la intensidad de ese reconocimiento y de las interacciones depende de las características del gobierno local que se encuentre en función.

\section{Reflexiones Finales}

Las características particulares de la provincia de Misiones hacen que este territorio sea de gran interés para el estudio de estrategias de desarrollo. En primer lugar por la presencia de numerosos y variados agentes sociales con cierta proximidad institucional y, en segundo lugar, la posibilidad de que su accionar conjunto se concrete por medio de la proximidad geográfica. Creemos que especialmente estos factores han permitido avanzar hacia un desarrollo local rural que puede ser ejemplificador para otros ámbitos territoriales de Argentina e incluso de América Latina.

En el caso de las ferias francas, consideramos que las mismas han logrado contribuir al desarrollo local rural. Estas experiencias han demostrado que las relaciones de proximidad entre las distintas organizaciones han sido de gran importancia, permitiendo la conformación, consolidación y difusión, de las ferias en todo el territorio misionero y ha servido como ejemplo para que en otros ámbitos territoriales del país se intente replicar (en las provincias de Corrientes, Salta, Santa Fe, Entre Ríos, Chaco y Catamarca). El accionar interinstitucional a nivel local permite actualmente la permanencia y vigencia de este proyecto comercial de la pequeña producción en las diferentes localidades donde han comenzado a funcionar.

Esta estrategia fue imitada no sólo como estrategia de comercialización sino también como estructura institucional de organización y participación. A partir de esta difusión, la misma alcanzó a una cantidad importante de productores a nivel provincial y llegó a tener reconocimiento regional y nacional y de esta manera se institucionalizó. Las ferias son un buen ejemplo de la difusión de conocimientos y de un modelo de organización exitosos.

Particularmente en lo que respecta a la vinculación MAM - PSA - INTA, creemos que estas tres organizaciones han logrado 
conformar un marco organizacional e institucional basado en la convivencia, cooperación, solidaridad, participación democrática y capacitación que ha permitido la concreción y proyección a futuro de las ferias en la provincia.

En síntesis, las ferias francas se han gestado en un marco institucional y han creado nuevas instituciones, que han definido una mejor calidad de vida de quienes participan; y han logrado replicar el modelo de convivencia, cooperación, solidaridad, participación democrática, organización y capacitación continua en el cual se han conformado.

\section{Notas:}

${ }^{1}$ La desregulación de los mercados y la apertura económica, junto con la paridad de la moneda nacional al dólar y el retiro del Estado de la esfera pública trajo aparejado una crisis económico social que se va profundizando en la década del '90 y continua en los primeros años del 2000.

2 Se trata de producciones distribuidas geográficamente en una provincia o región. Así, por ejemplo, el cultivo de la yerba mate se realiza principalmente en Misiones y en segundo lugar en Corrientes; y el algodón en la provincia de Chaco.

${ }^{3}$ Ya sea en organizaciones consolidadas -con cierta trayectoria institucional- como en procesos organizativos formales e informales (como por ejemplo, grupos de productores organizados para recibir asistencia técnica y financiera del Estado).

${ }^{4}$ El PROHUERTA, el Programa de Crédito y Apoyo Técnico para Pequeños Productores Agropecuarios del Noroeste Argentino (PPNEA), la Unidad de Coordinación de Planes y Proyectos de Investigaciones para productores minifundistas (Minifundio), el Cambio Rural, El Programa Social Agropecuario (PSA), el Programa de Desarrollo Rural para las provincias del NEA (PRODERNEA), el Proyecto de Desarrollo de pequeños productores agropecuarios (PROINDER) entre otros más focalizados tanto geográfica como sectorialmente (el Programa de Asistencia Subsidiada a Productores Ganaderos Minifundistas de la Patagonia, el Programa de Ordenamiento de Áreas tabacaleras (PRAT), etc.)

${ }^{5}$ El MOCASE surge formalmente el 4 de agosto de 1990. Sus comienzos pueden encontrarse en la primera Marcha por la tierra y la conformación de la Comisión Central de Campesinos de Los Juríes y de la Comisión Central de Pequeños Productores "Ashpa Sumaj” hacia 1989.

${ }^{6}$ El MAM es un gremio que nuclea a pequeños y medianos productores de la provincia de Misiones. Comienza su trabajo de formación en 1970 y se constituye definitivamente en una Asamblea realizada en Oberá en agosto de 1971.
${ }^{7}$ La feria está integrada por una serie de puestos móviles que se disponen en espacios públicos para la venta de productos de granja y huerta. Los mismos cuentan con un permiso municipal que dispone los días y horarios de funcionamiento. Los pequeños productores misioneros venden su producción contando con excensión impositiva, razón por la cual se denominan "ferias franca".

${ }^{8}$ En la provincia existen en la actualidad aproximadamente unas 45 ferias que nuclean alrededor de 2.000 pequeños productores agropecuarios. Según el Censo Nacional Agropecuario de 2002 habían en Misiones, un total de 27.072 explotaciones agropecuarias (o productores) de las cuales 14.745 pueden considerarse pequeñas (hasta $25 \mathrm{Ha}$. de superficie). Es decir, alrededor de un $14 \%$ de estos productores se encuentran participando de esta modalidad de comercialización.

${ }^{9}$ Se trata de localidades urbanas y rurales. La localidad más grande, Gran Posadas, tiene una población de 279.961 Hab., mientras que la más pequeña, Piñalito Sur, tiene $72 \mathrm{Hab}$. La población rural aglomerada se distribuye en 76 localidades. (Datos del CNPVyH de 2001, INDEC).

${ }^{10}$ Principalmente, a través del programa PROHUERTA y los proyectos de 'Minifundio'. A partir de 2003, este Instituto ha articulado todos los programas que venia ejecutando, en el marco del Programa Federal de Desarrollo Rural Sustentable (PROFEDER).

${ }^{11}$ Cabe destacar que la UTCP está conformada por representantes del gobierno nacional, del gobierno provincial, de organizaciones de pequeños productores, de ONG y de los beneficiarios. En la práctica, otras organizaciones y representantes de beneficiarios han sido incorporados en la UTCP. Si bien esta participación es informal, su trabajo con el programa se ha ido institucionalizando ya que tienen un rol activo en la organización y gestión del mismo.

${ }^{12}$ Sus principales objetivos son aumentar y diversificar el autoconsumo, promover y construir una propuesta de desarrollo agroecológico, articular con organizaciones que trabajan con pequeños productores, favorecer las organizaciones de productores, promoviendo que la mujer rural tenga iguales oportunidades, promover el acceso al mercado local favoreciendo el desarrollo local, apoyar con créditos, capacitación y asistencia técnica las actividades productivas que los colonos venían haciendo y abrir nuevas zonas de atención para la pequeña producción en el norte de la provincia.

${ }^{13}$ A partir del año 2001, el PSA tiene a su cargo la ejecución de un componente del PROINDER, otro programa de desarrollo rural nacional dirigido al sector pequeño productor de menores recursos, que otorga subsidios.

${ }^{14}$ La estructura del INTA en Misiones consta de un Centro Regional Provincial, dos Estaciones Experimentales Agropecuarias y varias Agencias de Extensión Rural en nueve localidades.

${ }^{15}$ De hecho, el INTA es un ente autárquico dependiente de la SAGPyA, desde la cual se ejecuta el PSA. 
Bibliografía citada

AGROMISIONES. Aprueban proyectos por $113 \mathrm{mil}$ pesos para apoyar a 120 familias de colonos. En www.agromisiones.com.ar. 2004.

APPENDINI, K. y NUIJTEN, M. El papel de las instituciones en contextos locales. En Revista de la CEPAL $\mathrm{N}^{\circ} 76$, p. 71-88, 2002.

BENENCIA, R. y FLOOD, C. Las ONG's y sus relaciones con el estado. Una aproximación al análisis del fenómeno en la Argentina. En Revista Realidad Económica 159, p. 54-68, 1998.

BOSCHERINI, F. y POMA, L. Territorio, conocimiento y competitividad de las empresas, Buenos Aires: Miño y Dávila Editores, 2000.

BRETT, E.A. Participation and Accountability in Development Managment. Documento de Trabajo, Development Studies Institute, London School of Economics. Londres. 1999.

BRUNO THÉRET, I. Nueva economía institucional, economía de las convenciones y teoría de la regulación: ¿hacia una síntesis institucionalista. En Noticias de la Regulación $\mathrm{N}^{\mathrm{o}}$ 35, p. 1-5, 2000.

CARBALLO GONZÁLEZ, C. Las ferias francas de Misiones. Actores y desafíos de un proceso de desarrollo local. Documento de Trabajo N ${ }^{o}$ 9, Centro de Estudios y Promoción Agraria, Buenos Aires. 2000.

CATTÁNEO, C.A. Algunos elementos para el análisis de la relación entre comercialización y pequeños productos agropecuarios. Documento de Trabajo, Programa Social Agropecuario, Secretaría de Agricultura, Ganadería Pesca y Alimentos de la Nación. Buenos Aires, 1999.

ESPINO AYALA, J. Instituciones y Economía. Una introducción al neoinstitucionalismo económico, México D.F.: Fondo de Cultura Económica, 1999.

GILLY J. y TORRE, A. Proximidad y dinámicas territoriales. En: Boscherini, F. y Poma L., Territorio, conocimiento y competitividad de las empresas, Buenos Aires: Miño y Dávila Editores, 2000.
INDEC. Provincia de Misiones, Censo Nacional de Población, Vivienda y Hogares. Buenos Aires, 2001.

KLIKSBERG, B. Seis tesis no concencionales sobre participación. En: Kliksberg, B., Tomassini, L. (comp), Capital social y cultura: claves estratégicas para el desarrollo, Buenos Aires: BID/Fundación F. Herrera/ Universidad de Mariland/FCE, 2000.

MANZANAL, M. Instituciones, territorio y gestión del desarrollo rural-local (teoría y praxis desde la realidad del norte argentino). En VIII SEMINÁRIO INTERNACIONAL DA REDE IBERO-AMERICANA DE INVESTIGADORES SOBRE GLOBALIZAÇÃO E TERRITÓRIO (RII), 2004, Río de Janeiro. Anales del VIII Seminario Internacional de la RII, Río de Janeiro: Rede Ibero-Americana de Investigadores sobre Globalização e Território, 2004

MONTIEL, S. Los pequeños productores agrícolas de Misiones y sus formas de representación política gremial. Informe Final, PISPAD, Universidad Nacional de Misiones, Argentina. 1997.

MONTIEL, S. Procesos de participación y Cambio en el Movimiento Agrario Misionero, Tesis de grado Lic. en Antropología Social, Posadas: UNaM, 2000.

NORTH, D.C. The new institutional economics and third world development. En: J Harriss \& others, The new institutional economics and third world development, Londres: Routledge, 1995.

NORTH, D. C. Instituciones, cambio institucional y desempeño económico. México D.F.: Fondo de Cultura Económica, 1993.

PEREIRA, S. G. y TAIPALE, P. Estrategias innovativas locales-rurales y sus instituciones: el caso de las ferias francas en la provincia de Misiones, Argentina. En: II CONGRESO NÓRDICO DE ESTUDIOS LATINOAMERICANOS, NOL@N, 2004, Helsinki. Anales... Helsinki: Universidad de Helsinki, 2004.

PSA. Estudio del impacto de las ferias francas en la provincia de Misiones, Documento de Trabajo, Unidad Técnica de Coordinación Provincial de Misiones, Eldorado: Secretaría de Agricultura, Ganadería, Pesca y Alimentación de la Nación, 1997. 